\title{
An improved device for sampling bacterial populations on blankets
}

\author{
BY A. B. McQUADE \\ Experimental Officer
}

\author{
AND W. J. A. SUTHERLAND
}

Senior Laboratory Craftsman

Division of Protein Chemistry, C.S.I.R.O. Wool Research Laboratories, 343 Royal Parade, Parkeville, N. 2 (Melbourne), Victoria, Australia

(Received 21 December 1959)

One of the major difficulties in determining the cleanliness of blankets for use in hospital wards is the estimation of bacterial contamination remaining on the blanket after washing. Present procedures are either cumbersome or not readily reproducible. Procedures for measuring bacterial contamination on fabrics may be based on dispersion of the bacteria as an aqueous or as an airborne cloud. As aerial sampling has the advantages that it may be rapid and simple and can be used to sample blankets which have been washed with a bactericide the possibilities of this principle were investigated. A simple method has been developed (Blowers \& Wallace, 1955) in which the blanket is scraped manually by the edge of an agar plate so that the bacterial dust is thrown on to the exposed agar surface, but this procedure is difficult to control. There are wide differences in surface properties of blankets, and consequently in the amount of fibrous material shaved off by the Petri dishes. Puck, Robertson, Wise, Loosli \& Lemon (1946) worked on the principle of hitting an area of taut blanket and sampling the aerial cloud so formed, but as their apparatus was not convenient for routine sampling in wards an improved version has been developed.

As can be seen from Pl. 1 the device comprises a clamp to grip the blanket, a receiver to support the blanket and to contain Petri dishes, and a percussion instrument. The clamping circle is gimbal mounted and spring loaded to the toggle arm in order to allow for varying blanket thicknesses, and it has a bevelled circular surface underneath, which wedges the blanket tightly in the mouth of the receiver. The apparatus is shown assembled in Pl. 2. The toggle-action clamp is closed and the percussion instrument in position for striking the blanket by a freely falling steel ball. This ball is attached by a pivoted T-bar to a circle around the slotted guiding cylinder as shown in Text-fig. 1. The cylinder protudes through an annular support so that the cylinder just touches the surface of the taut blanket. The length of the T-bar is such that the falling ball is stopped only by the blanket. All parts may be steam sterilized or treated with $70 \%$ ethanol in water.

Percussion procedures remove only a very small fraction of the bacteria on a blanket, therefore this apparatus was designed to sample a fairly large area. 
Consequently the apparatus is a little bulky and it is necessary to remove the blanket from its position on the bed. The minimum area which may be sampled by this apparatus is $400 \mathrm{sq} . \mathrm{cm}$.; the receivers (paint cans) are $250 \mathrm{~cm}$. diameter and $250 \mathrm{~cm}$. high; the steel ball (ball bearing) is $3 \mathrm{~cm}$. in diameter and weighs $250 \mathrm{~g}$. The ball falls $30 \mathrm{~cm}$. According to the density of the population of bacteria being sampled the number of falls per sampling may be adjusted by trial and error so that the plate counts fall within the required range. We have found that ten falls give counts of the order of $10^{3}$ per plate $8.5 \mathrm{~cm}$. diameter from blankets which have been in hospital wards for about 10 days.

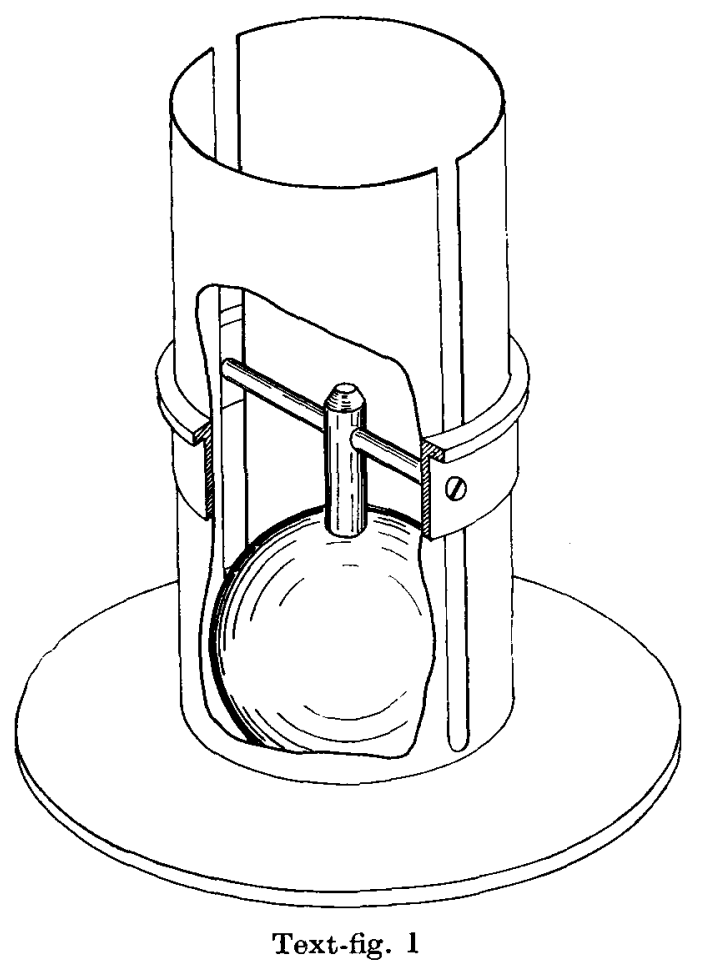

By visual inspection it could be seen that the distribution of bacterial colonies on plates from the percussion procedure were more evenly distributed than those from the scraping procedure. In the latter case the colonies were distributed fanwise around points of contact of the edge of the plate with the blanket. Some plates from the percussion procedure were examined statistically and it was found that the colonies were randomly distributed over the agar plate.

The sampling of blankets was arranged by Dr R. B. Maynard (Senior Pathologist) and Mr K. G. Pope (Senior Bacteriologist) at the Repatriation General Hospital, Victoria.

\section{REFERENCES}

Blowers, R. \& Wallace, K. R. (1955). Lancet, i, 1250.

Puck, T. T., Robertson, O. H., Wise, H., Loosir, C. G. \& Lemon, H. M. (1946). Amer. J. Hyg. 43, 91. 


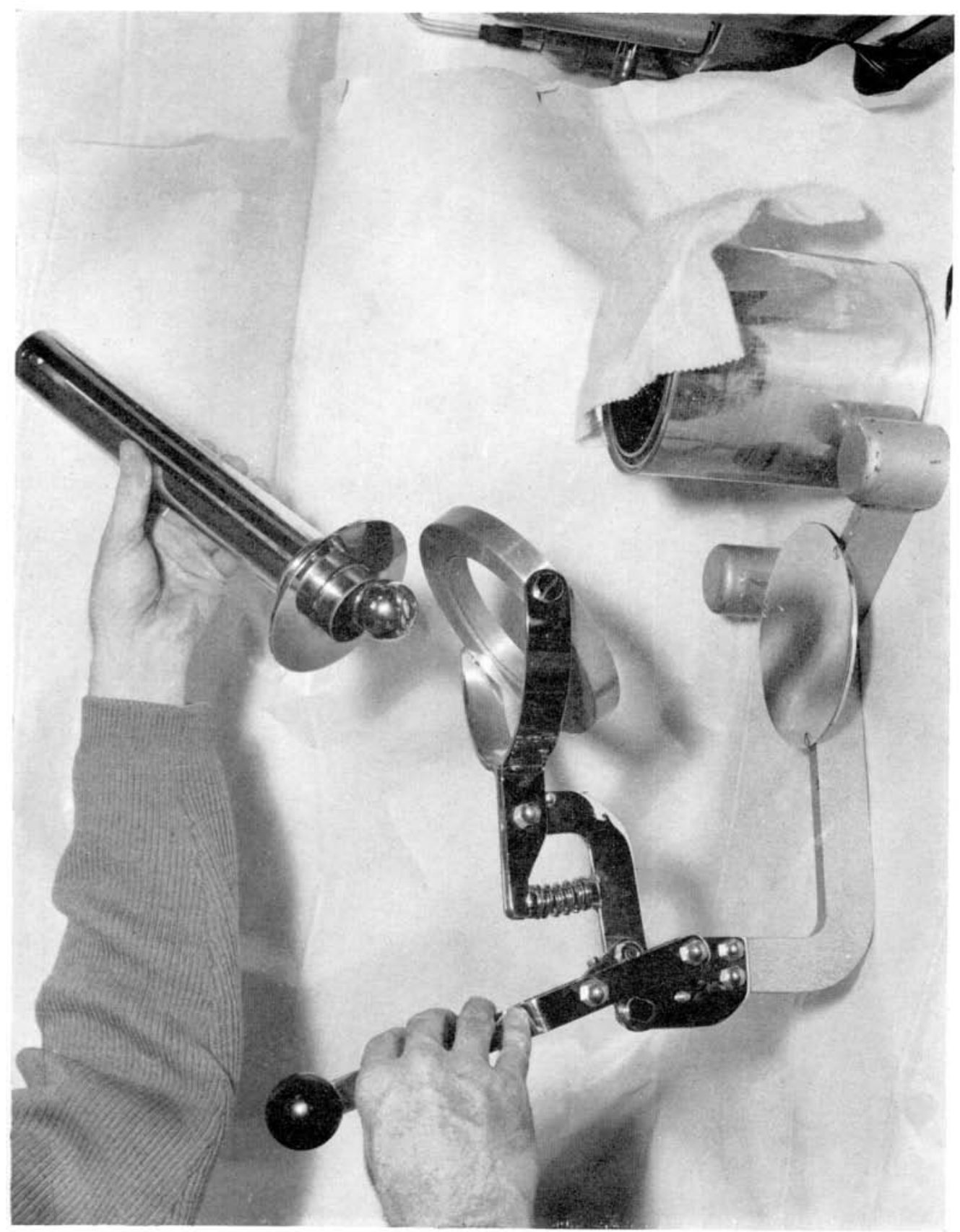

A. B. MCQUADE AND W. J. A. SUTHERLAND 
Journal of Hygiene, Vol. 58, No. 2

Plate 2

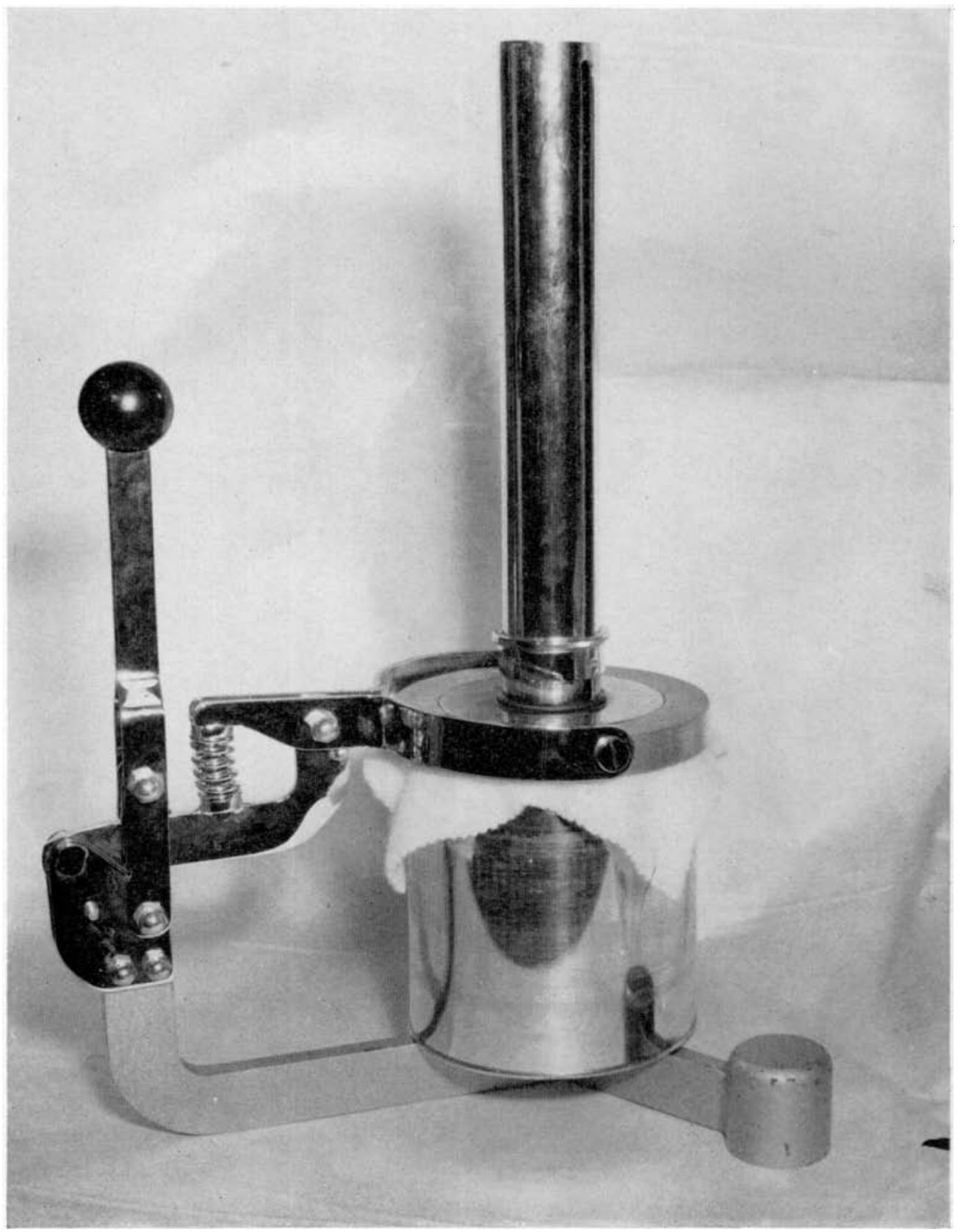

A. B. McQUADE ANd W. J. A. SUTHERLAND) 